\title{
TIRAR O RISCO: DECALQUES DA BIBLIOTECA PARA-LUZ
}

Daisy Turrer

Daisy Leite Turrer é artista, pesquisadora e professora. Doutora em Literatura Comparada e mestre em Literatura Brasileira pela Faculdade de Letras/UFMG. Professora de Gravura do Departamento de Artes Plásticas e do Programa de pós-graduação em Artes da Escola de Belas Artes da Universidade Federal de Minas Gerais. Dedica-se aos estudos sobre a imagem a escrita e o livro e às pesquisas sobre os desdobramentos da gravur em instalações, fotografias, objetos e edições.
Tirar o risco: decalques da Biblioteca Para-Luz disponibiliza ao leitor folhas avulsas, registros do processo de elaboração da gravura, o que a cerca para além das matrizes impressas, mas que nela não aparece: o movimento das provas de estado, os papéis transparentes, os desenhos, os carbonos, as imagens invertidas, os para-sóis, as talagarças. Um ensaio que envolve dois gestos diferentes e semelhantes, ao mesmo tempo, o de gravar e o de desenhar: o de "fazer o risco", uma incisão, recortar, elabora uma matriz e o de "tirar o risco", copiar, decalcar, transcrever.

Uma experiência que sobrevive da tentativa de colher a ambiguidade desses dois gestos, pois o que se quer fixar através da luz dos parasóis não se fixa, e o que fica registrado já são outras sombras, imagens que fogem da impressão em stencil com o pó de grafite sobre papel. São os parasóis, que se mostram agora como potência. E ao se mostrarem, o jogo recomeça, propondo-se, nopotência. E ao se mostrarem, o jogo recomeça, propondo-se, novamente, a neles buscar o que nele não está. Nesse lugar em que dios, e o que ela grafa é a sombra da sombra que já se foi. 


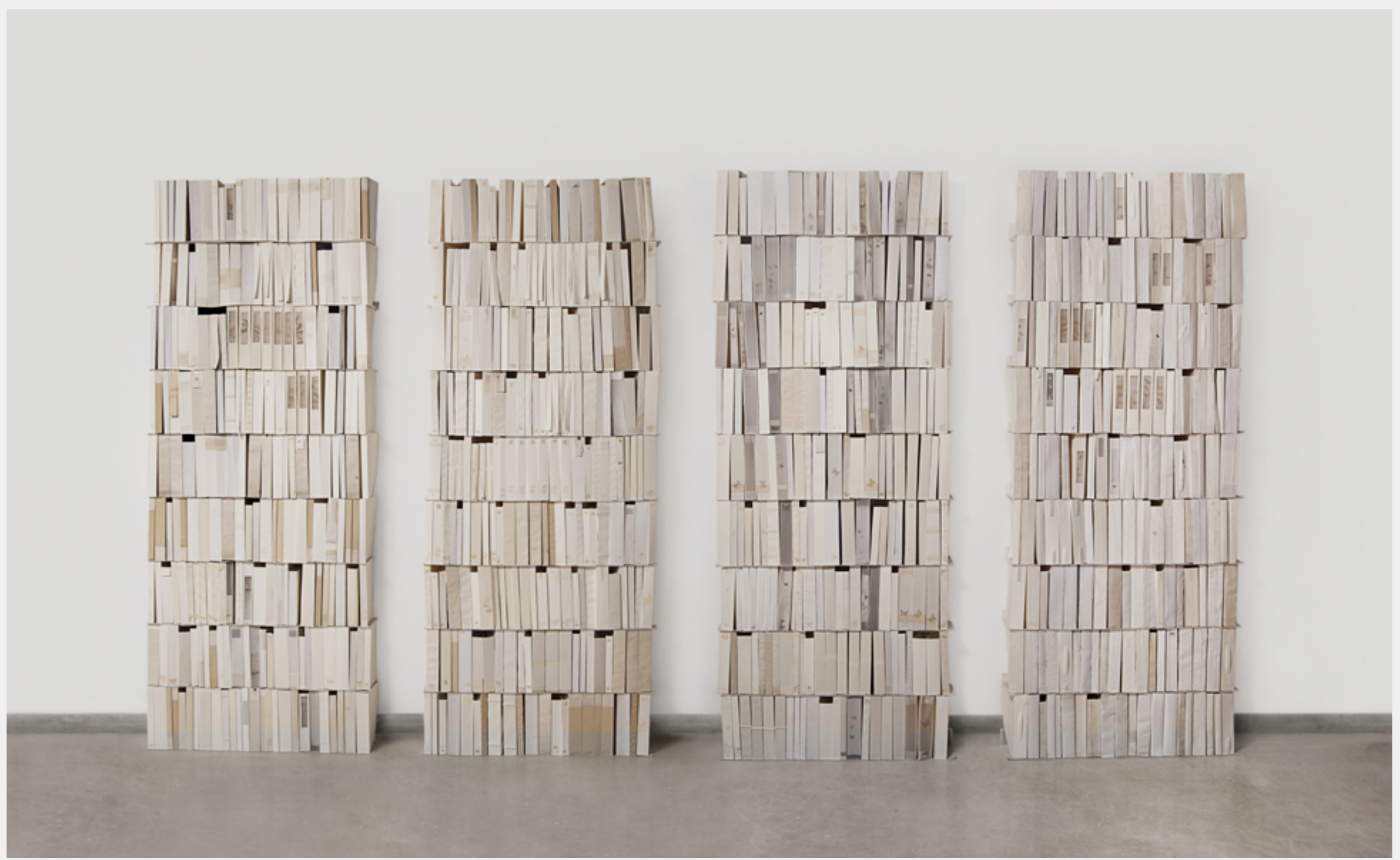

Biblioteca Para-Luz Foto: Miguel Aun

\section{Poéticas}




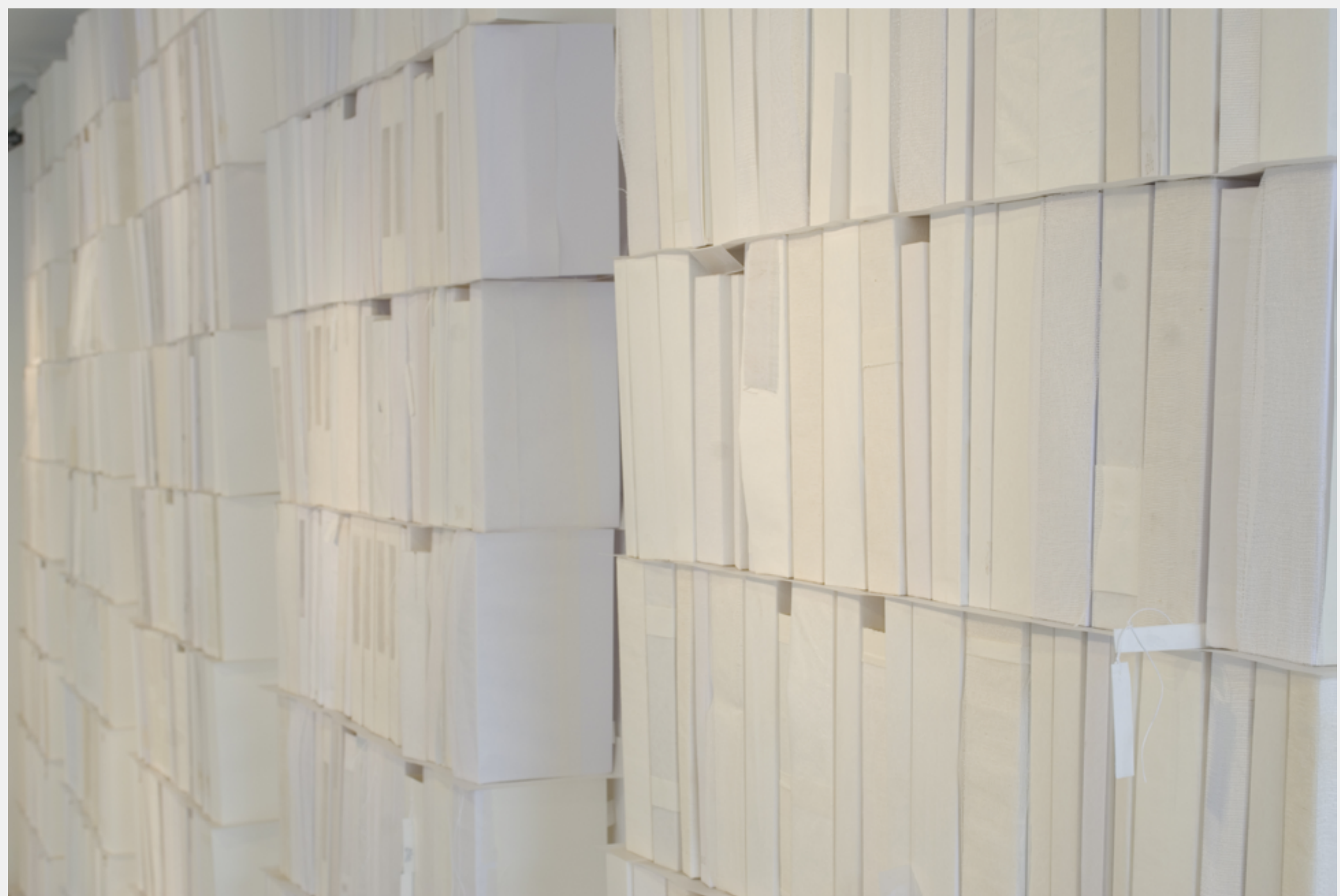

Biblioteca Para-Luz 


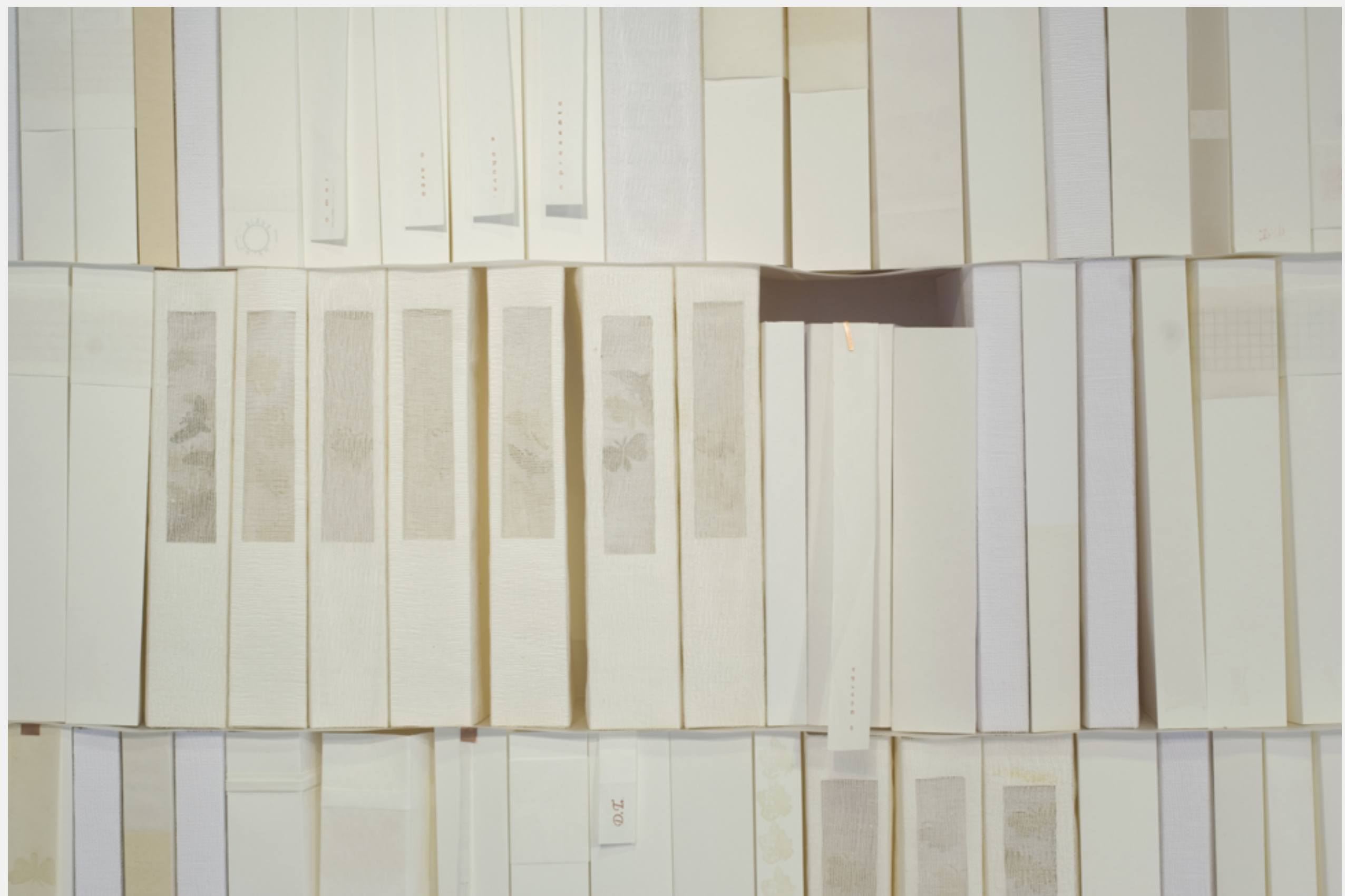

Biblioteca Para-Luz 


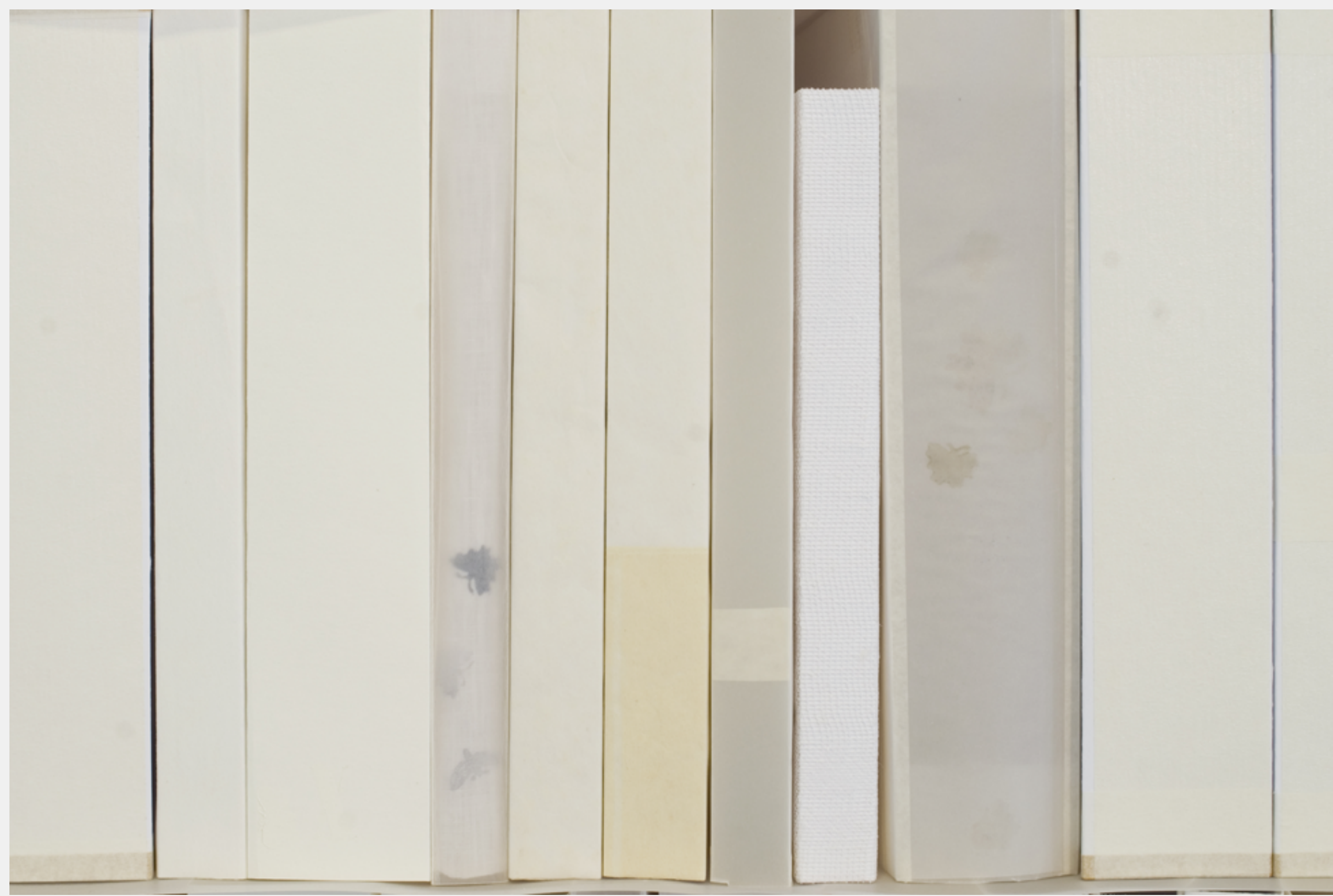

Biblioteca Para-Luz Foto: André Hauck 


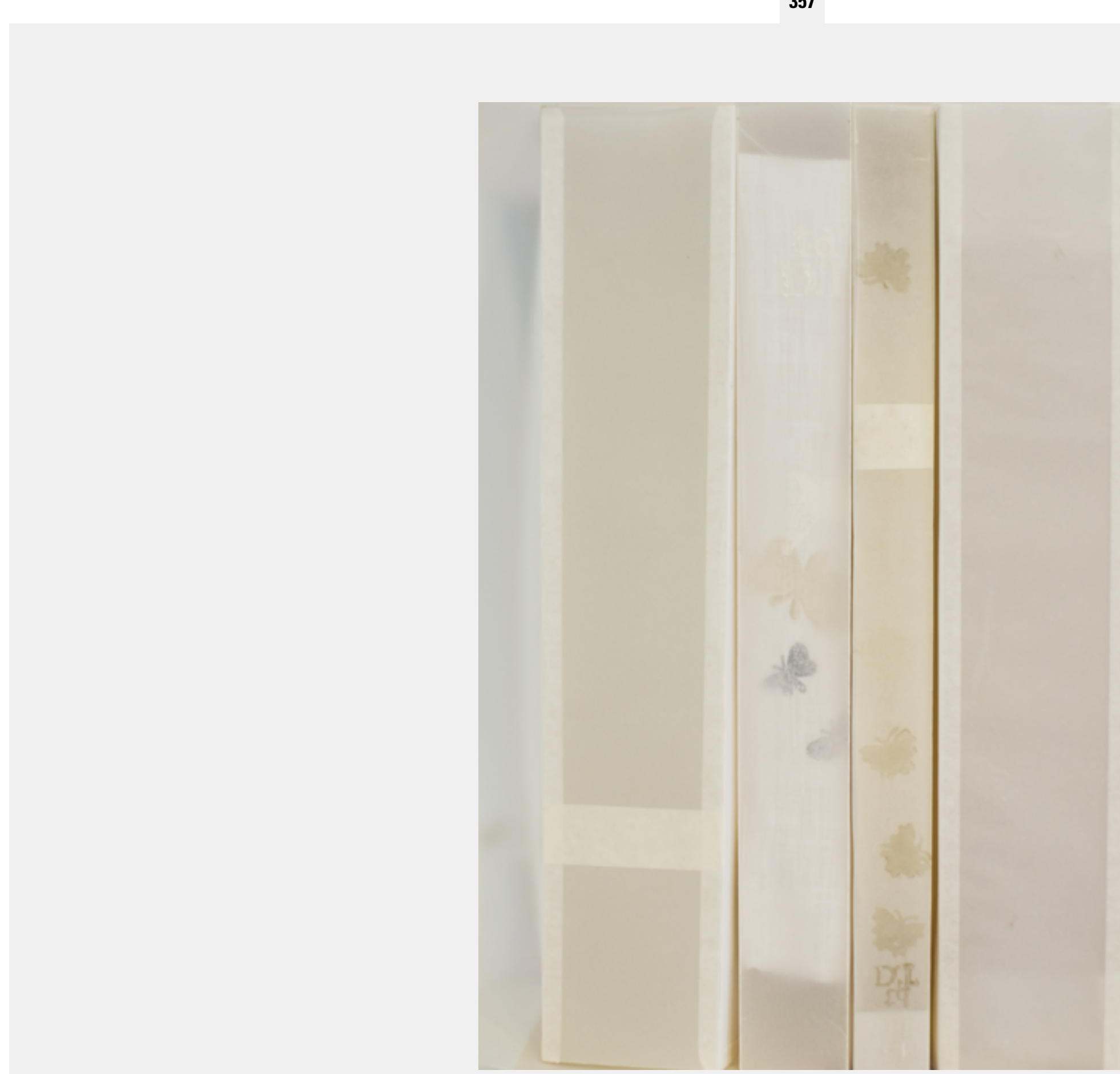

Biblioteca Para-Luz Foto: André Hauck 


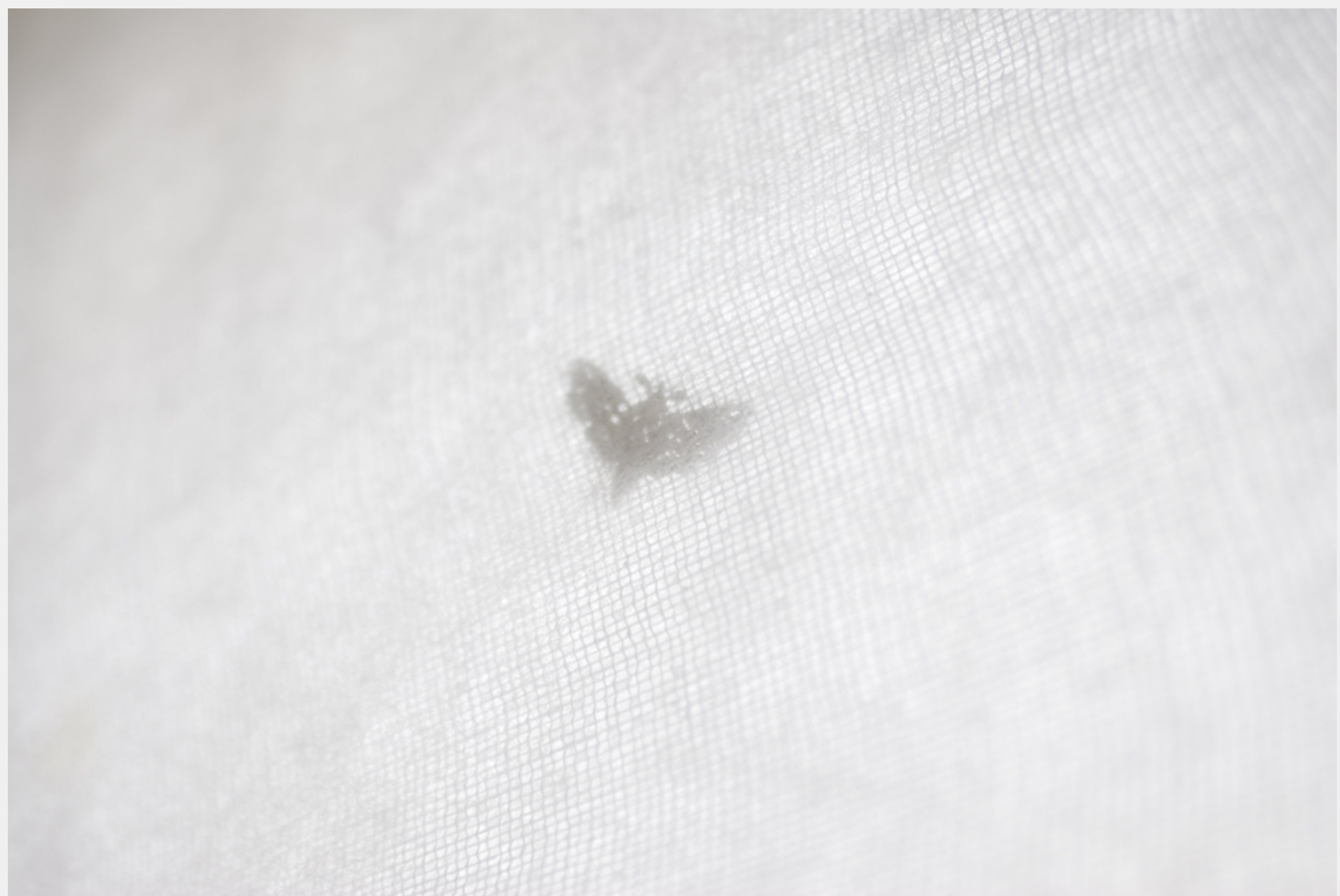

Biblioteca Para-Luz Foto: André Hauck 


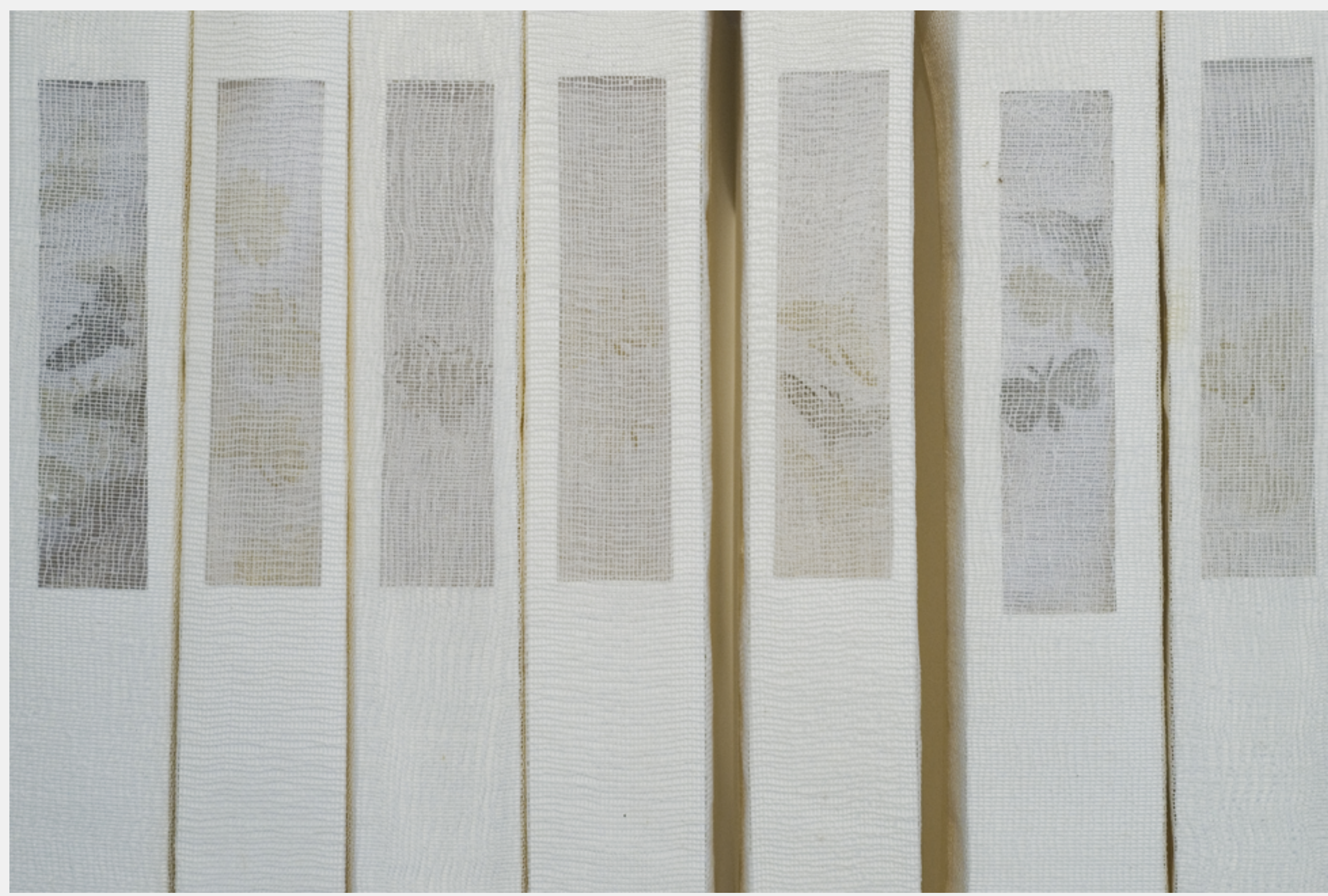

Biblioteca Para-Luz Foto: André Hauck

EM TESE BELO HORIZONTE

v. 22

N. 3

SET.-DEZ. 2016

TURRER. Tirar o risco: decalques da Biblioteca Para-Luz

P. 352-379 


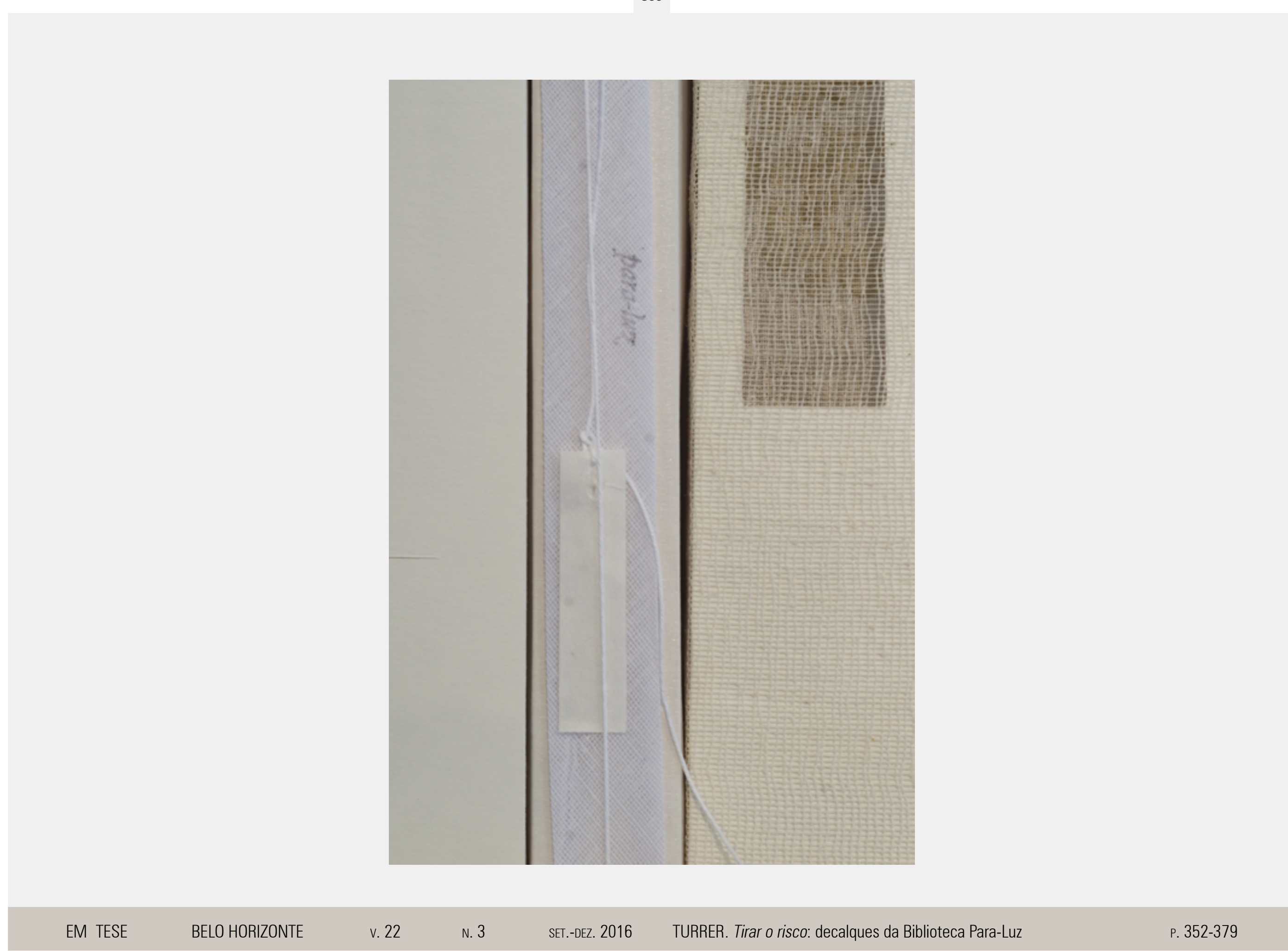

Biblioteca Para-Luz

Foto: André Hauck

Poéticas 


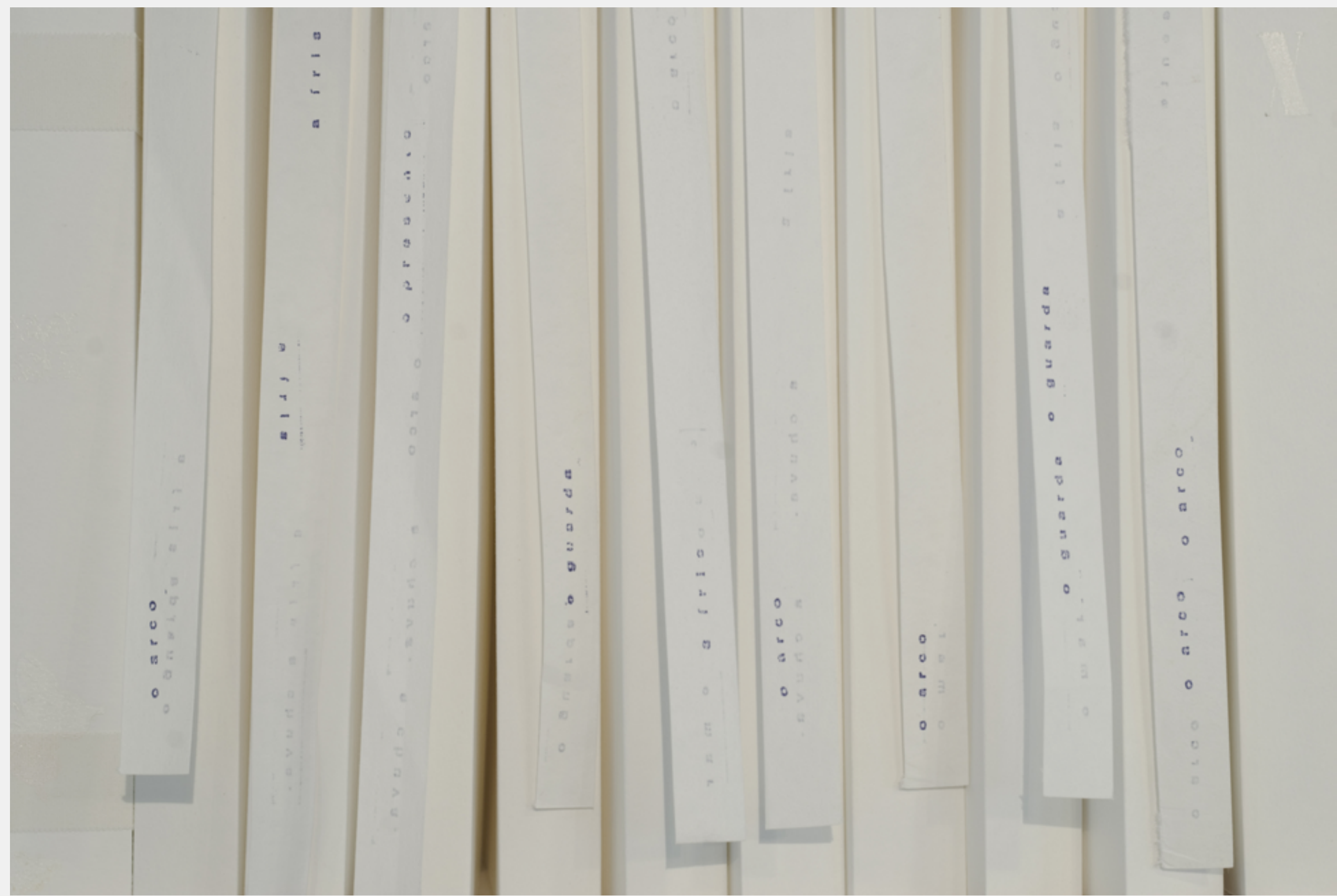

Biblioteca Para-Luz Foto: André Hauck

EM TESE BELO HORIZONTE

v. 22

N. 3

SET.-DEZ. 2016

TURRER. Tirar o risco: decalques da Biblioteca Para-Luz

P. $352-379$ 



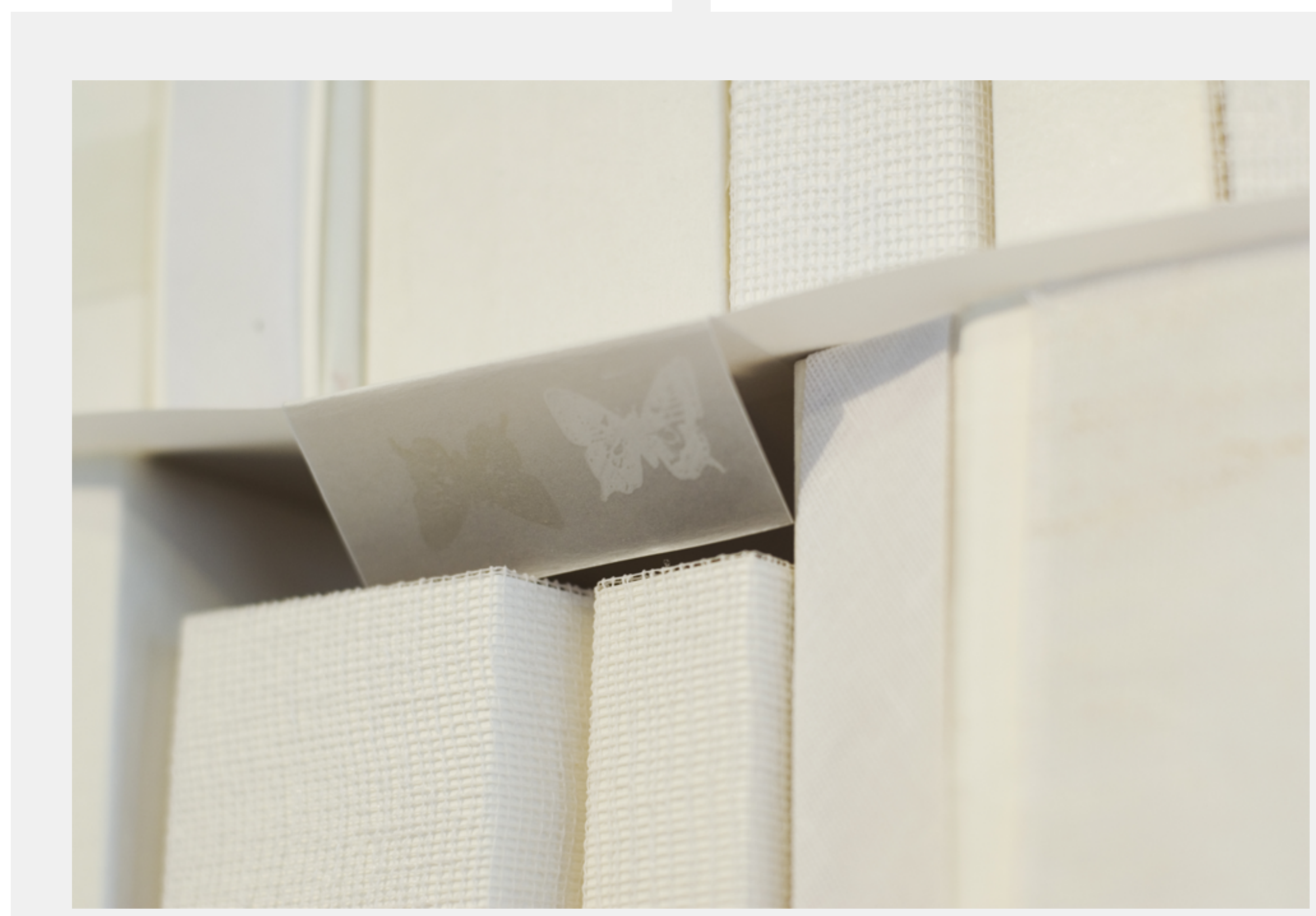

Biblioteca Para-Luz Foto: André Hauck

EM TESE

BELO HORIZONTE

v. 22

N. 3

SET.-DEZ. 2016

TURRER. Tirar o risco: decalques da Biblioteca Para-Luz

P. $352-379$ 


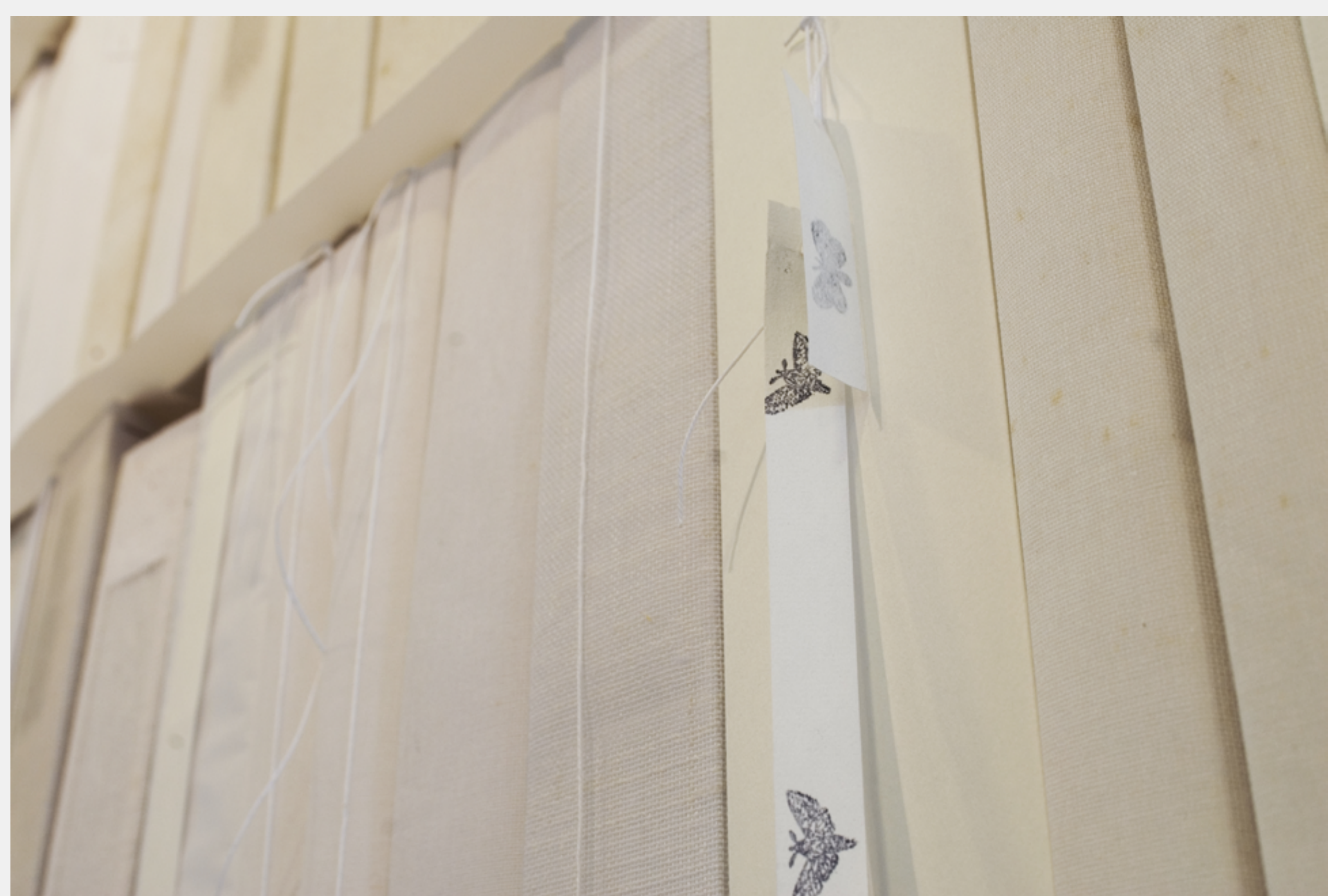

Biblioteca Para-Luz Foto: André Hauck

EM TESE

BELO HORIZONTE

v. 22

N. 3

SET.-DEZ. 2016

TURRER. Tirar o risco: decalques da Biblioteca Para-Luz

P. 352-379 


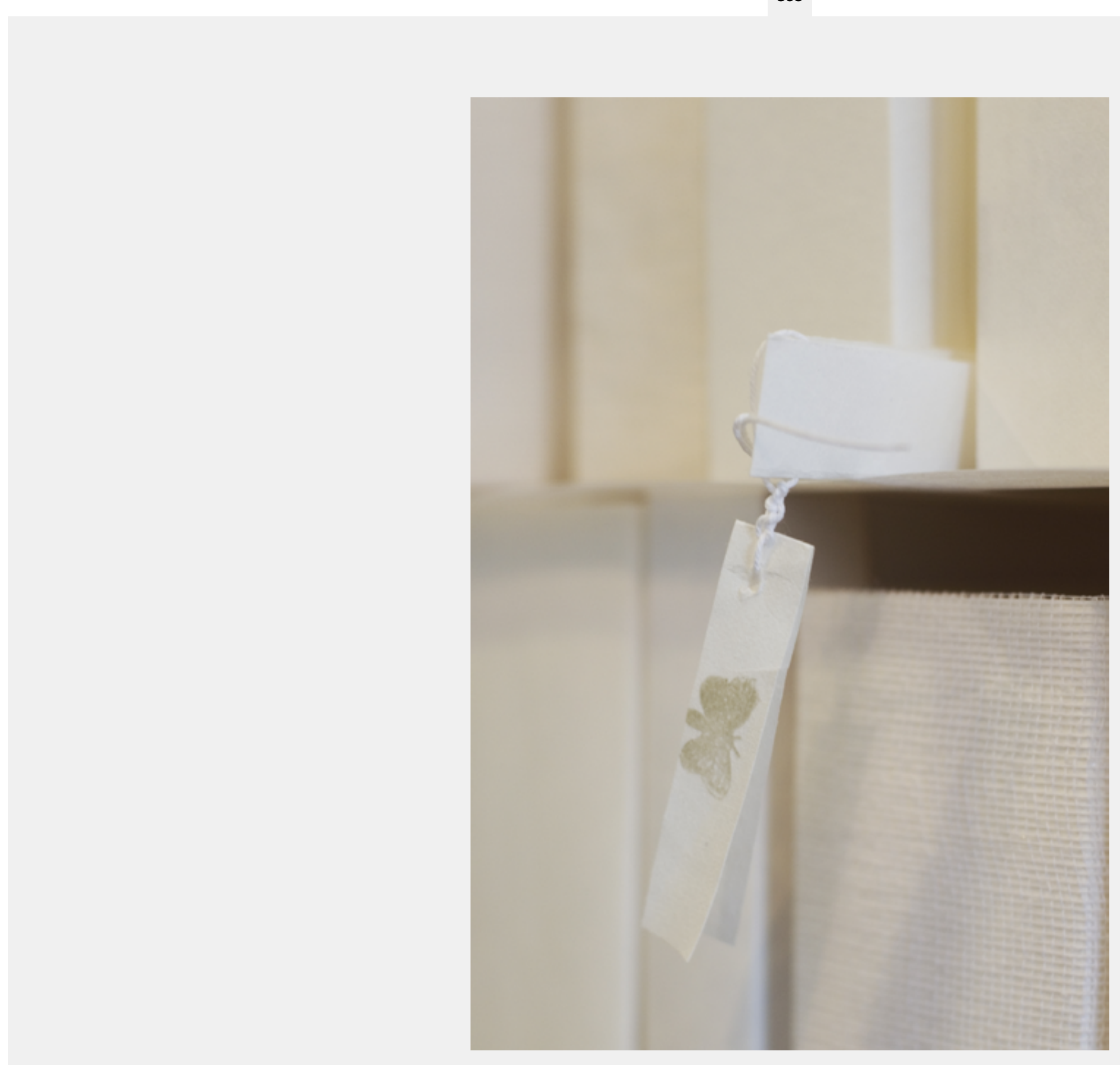

Biblioteca Para-Luz

Foto: André Hauck 


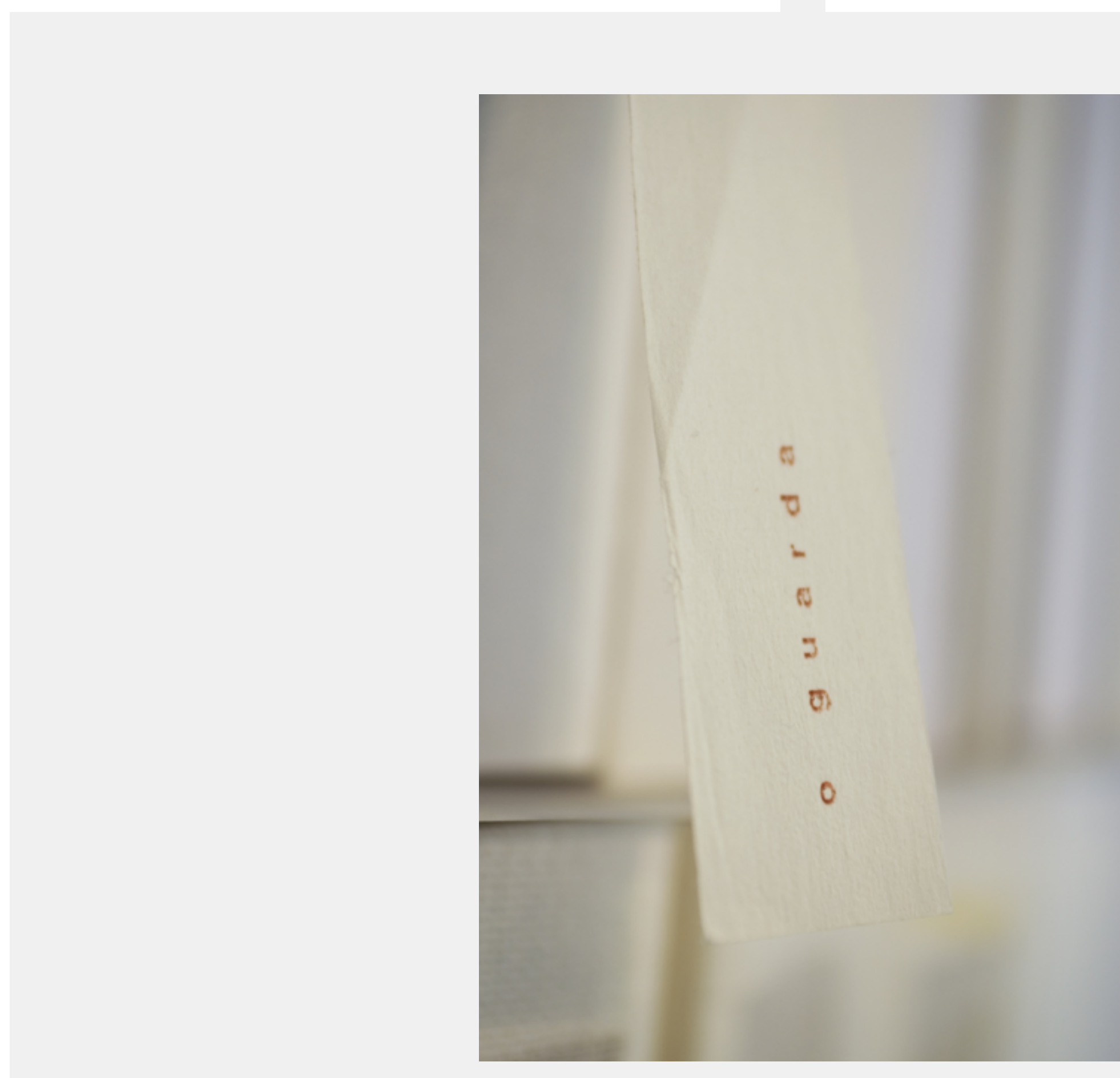

Biblioteca Para-Luz

Foto: André Hauck 


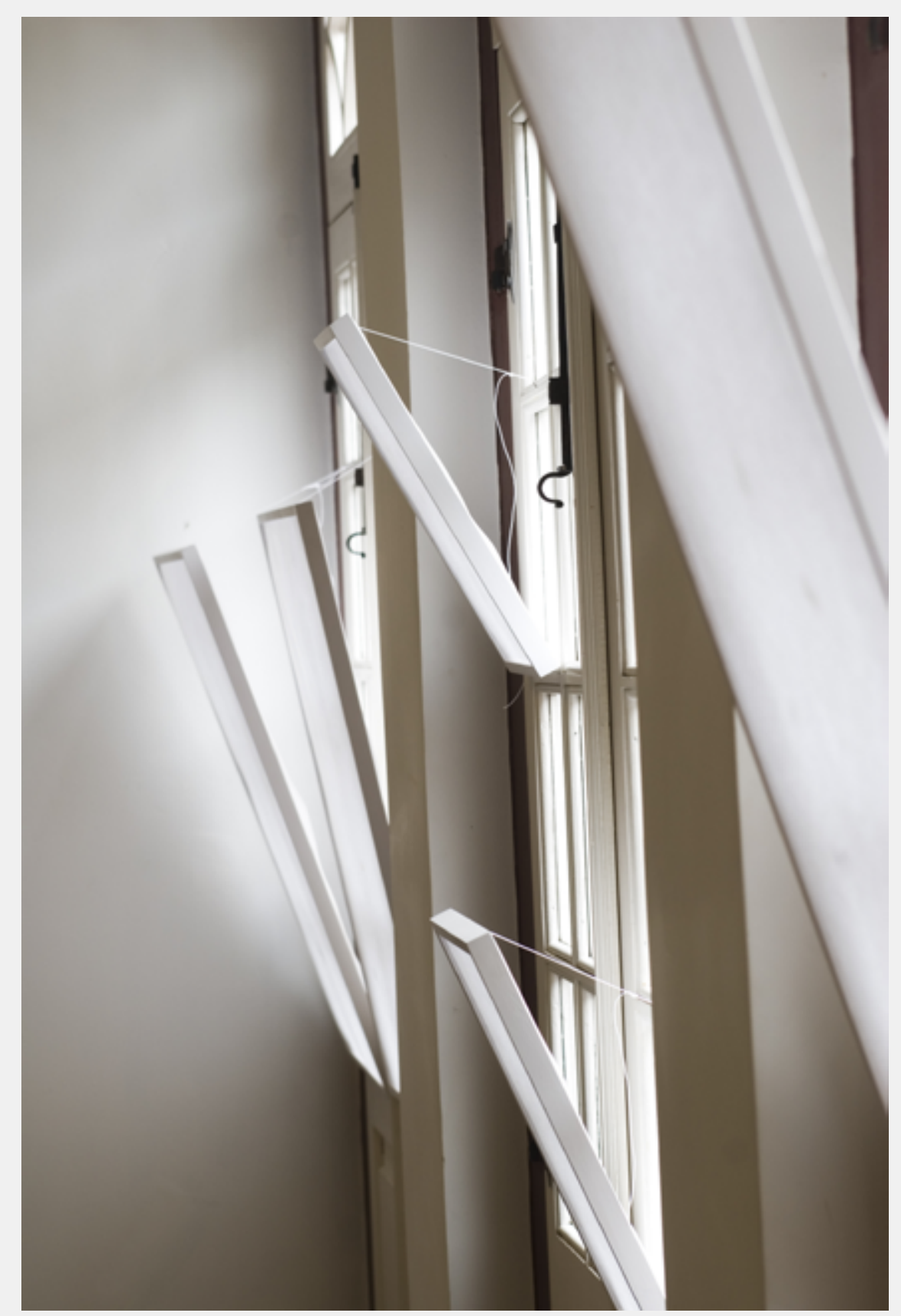

Biblioteca Para-Luz

Foto: Margarida Campos 


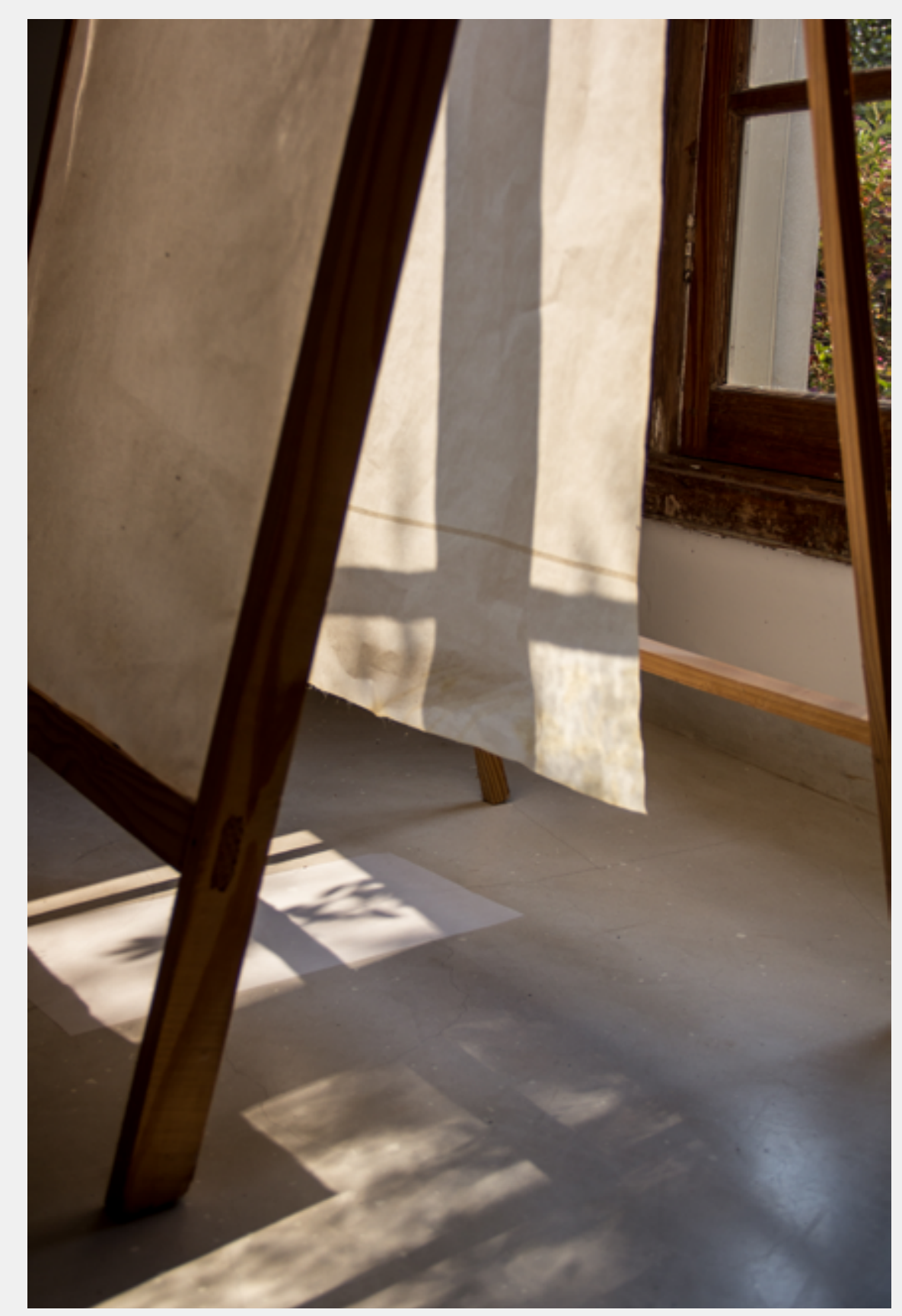

Biblioteca Para-Luz

Foto: Margarida Campos 


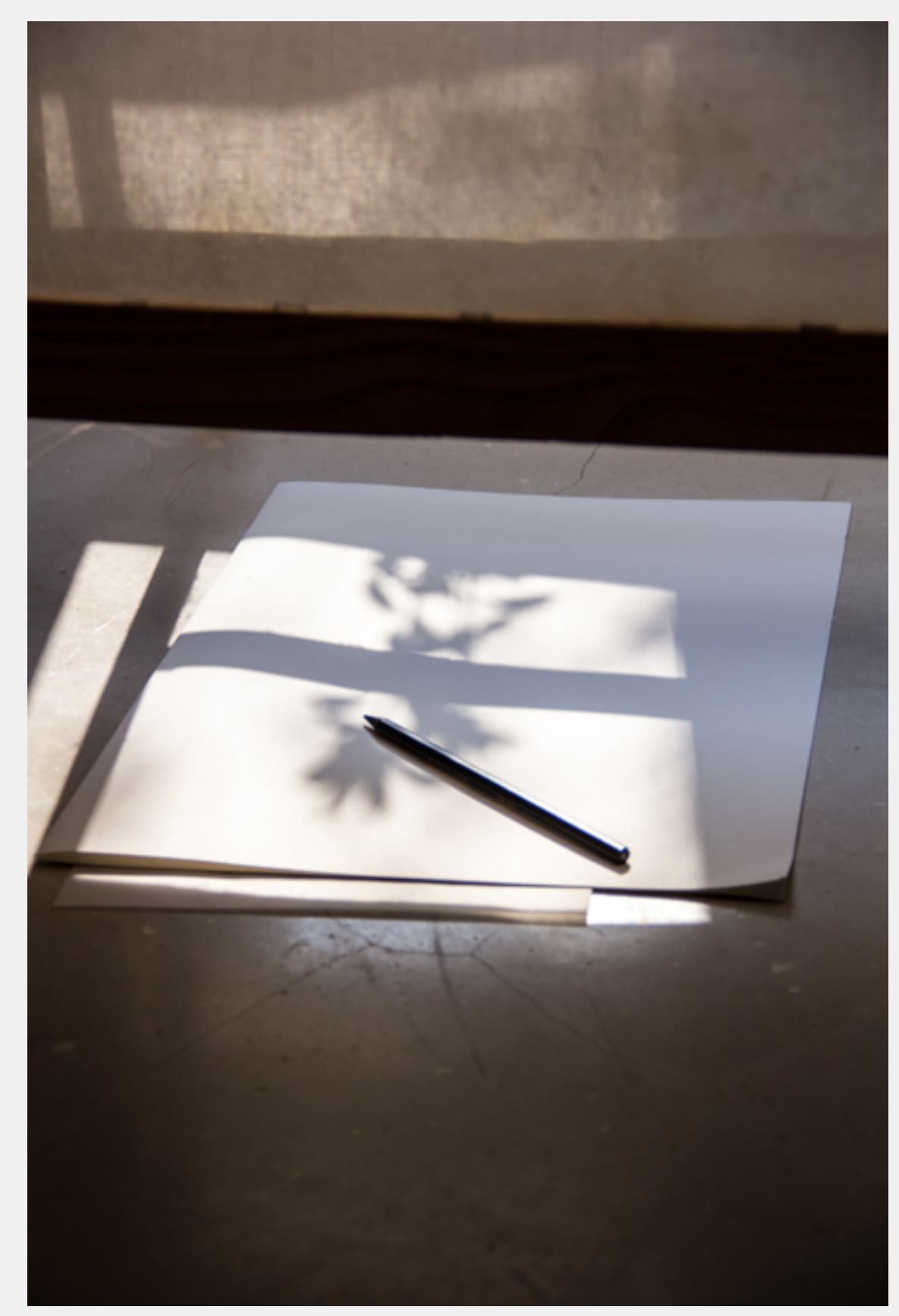




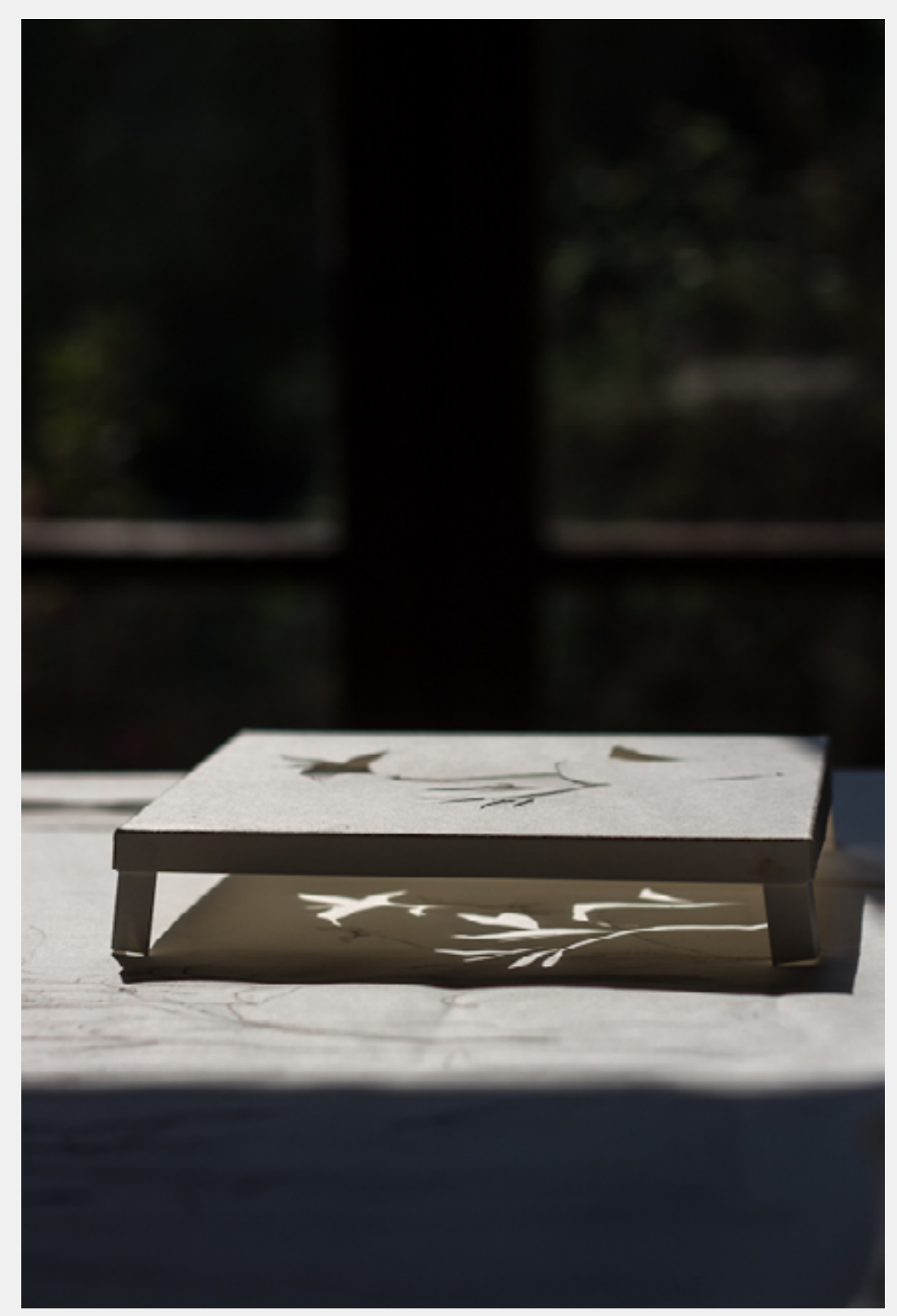

Biblioteca Para-Luz

Foto: Margarida Campos 


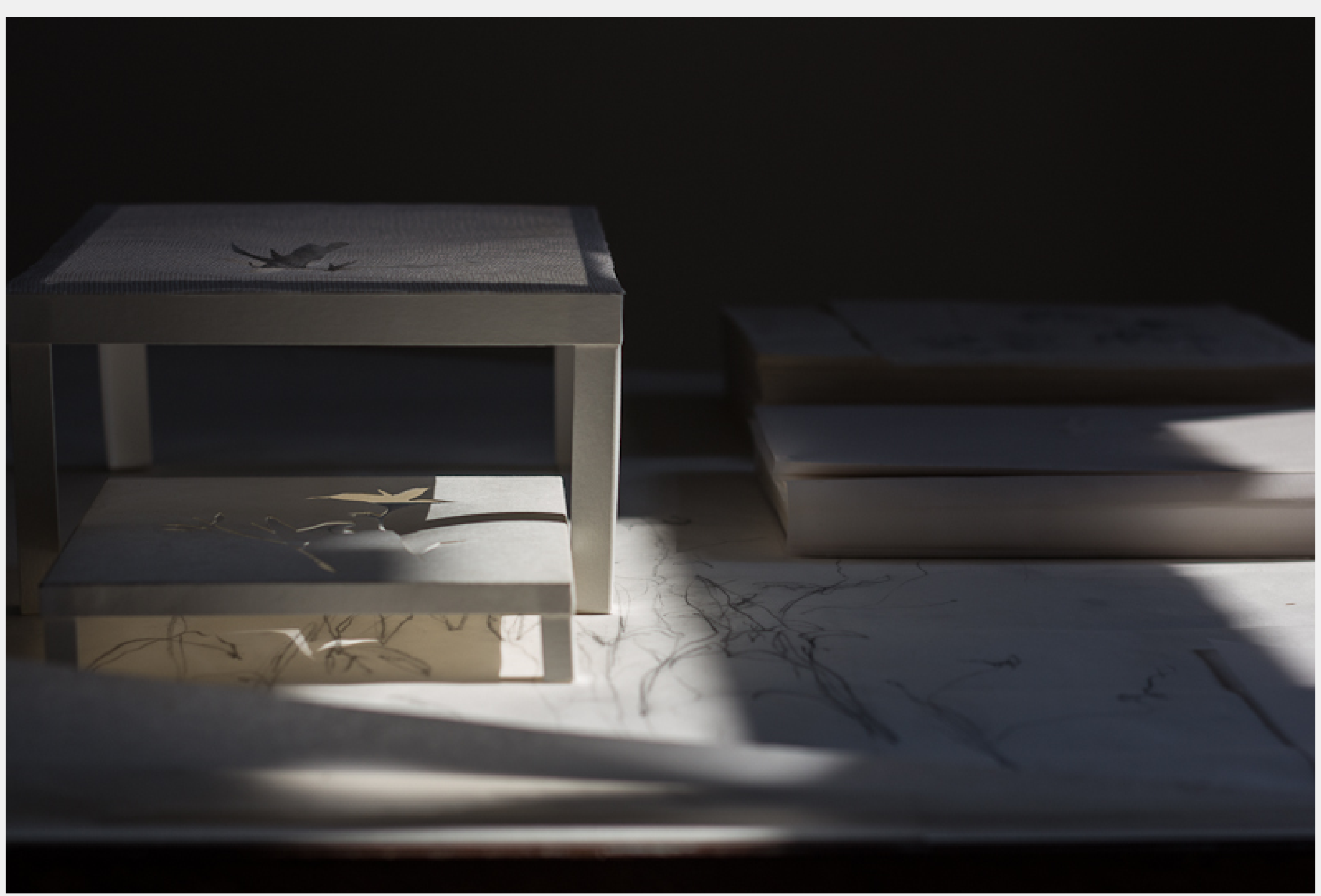

Biblioteca Para-Luz 


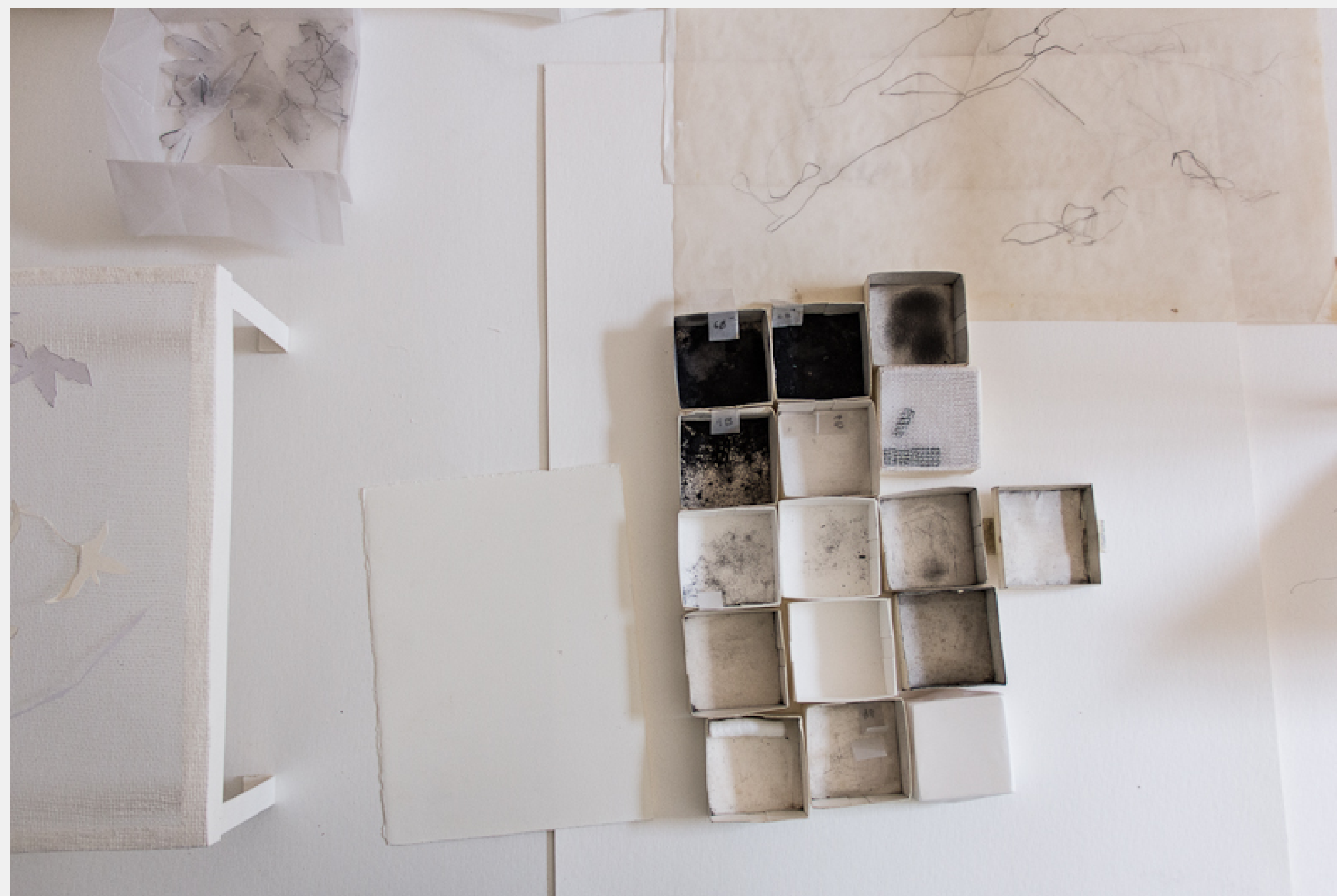

Biblioteca Para-Luz

Foto: Margarida Campos

EM TESE

BELO HORIZONTE

v. 22

N. 3

SET.-DEZ. 2016

TURRER. Tirar o risco: decalques da Biblioteca Para-Luz

P. $352-379$ 


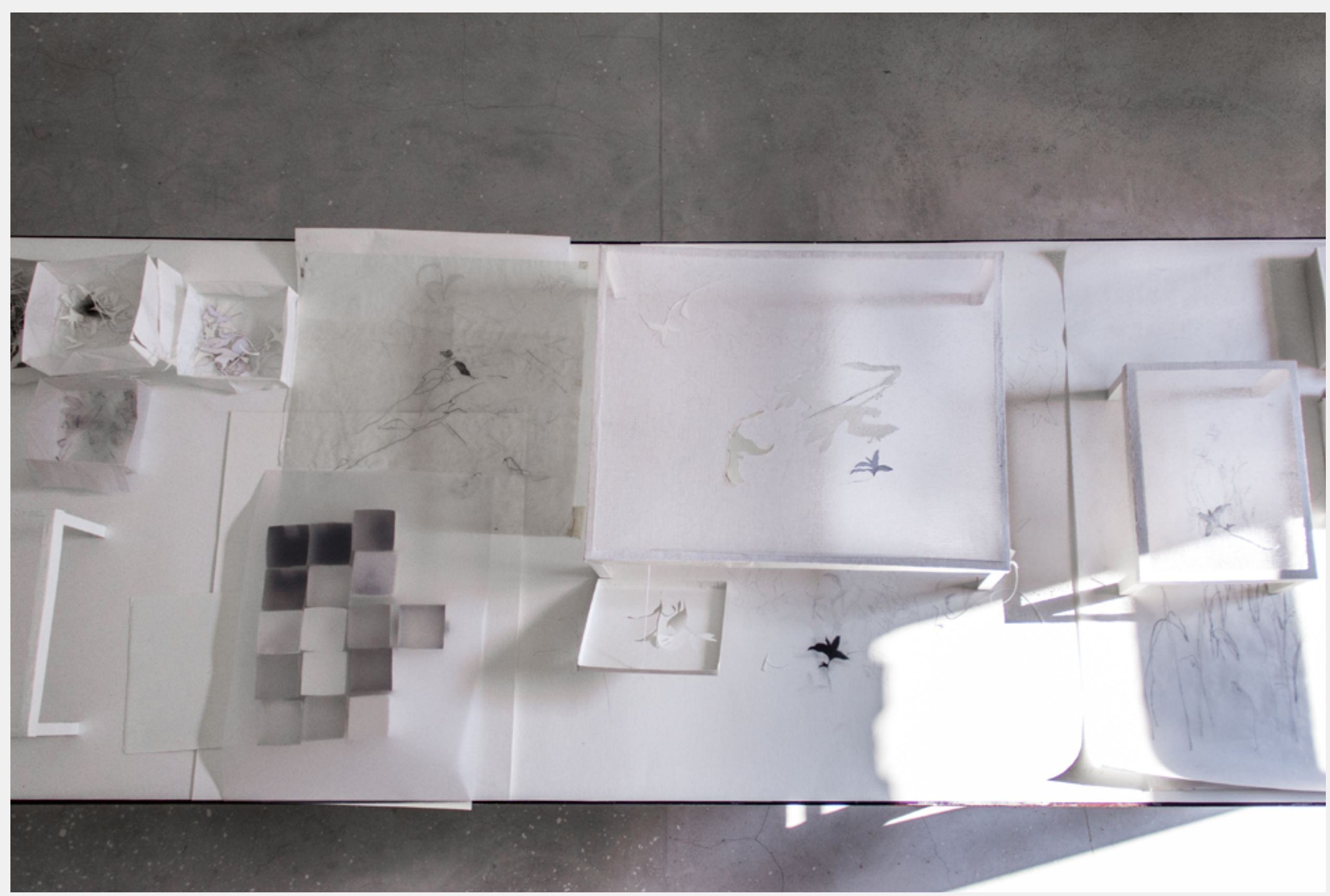

Biblioteca Para-Luz Foto: Margarida Campos

EM TESE

BELO HORIZONTE

v. 22

N. 3

SET.-DEZ. 2016

TURRER. Tirar o risco: decalques da Biblioteca Para-Luz

P. $352-379$ 


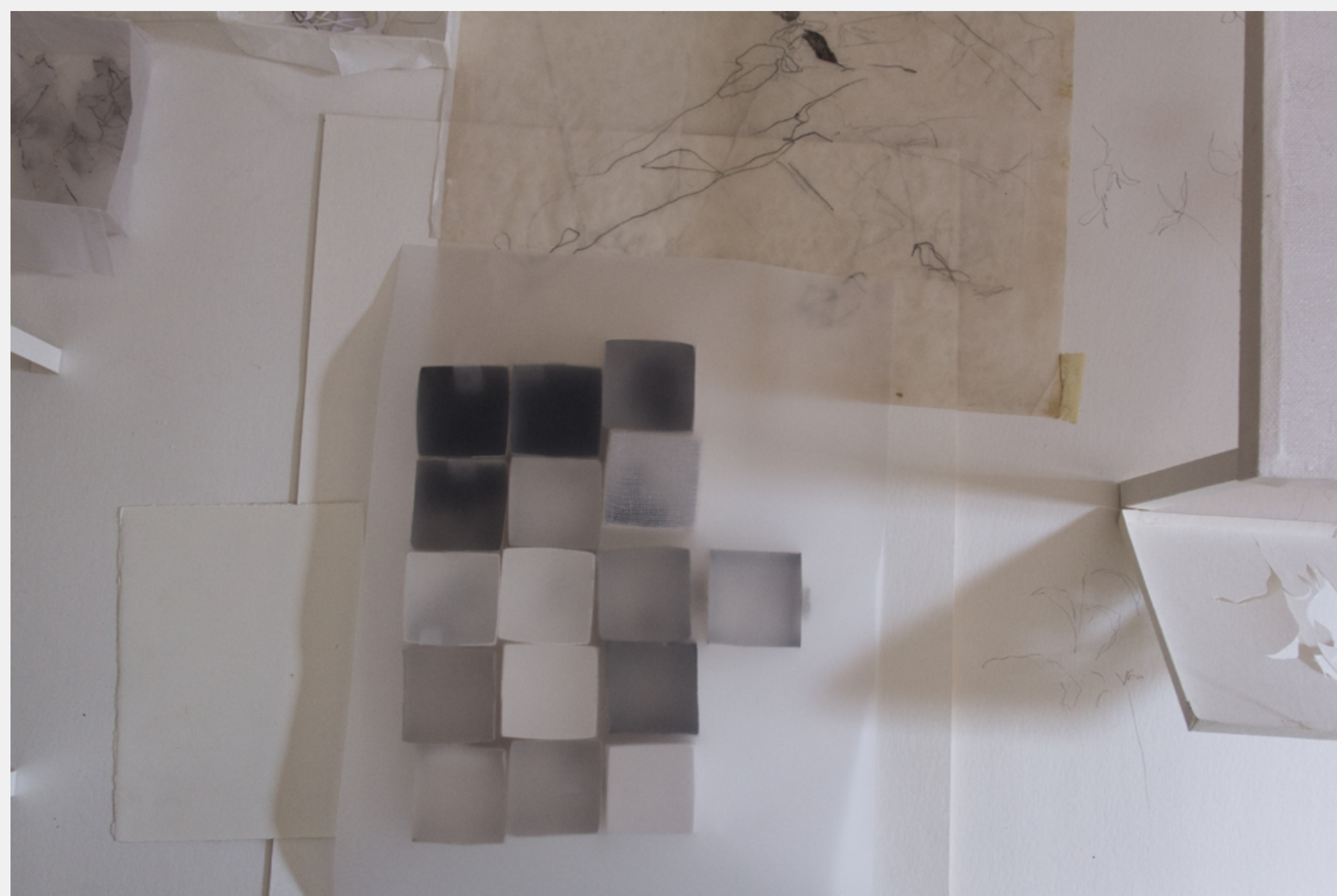

Biblioteca Para-Luz Foto: Margarida Campos

EM TESE

BELO HORIZONTE

v. 22

N. 3

SET.-DEZ. 2016

TURRER. Tirar o risco: decalques da Biblioteca Para-Luz

P. $352-379$ 


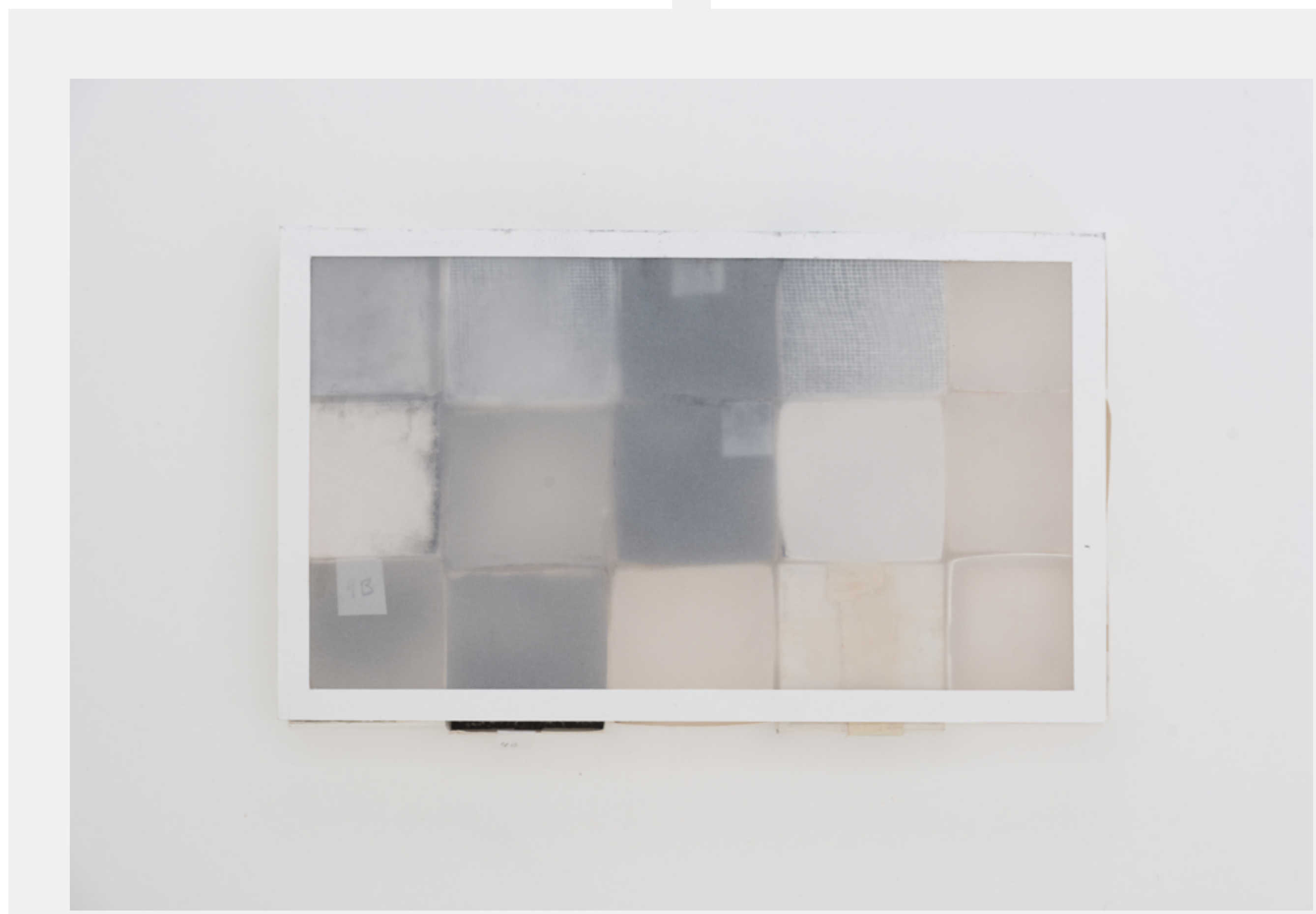

Biblioteca Para-Luz Foto: Ícaro Moreno 


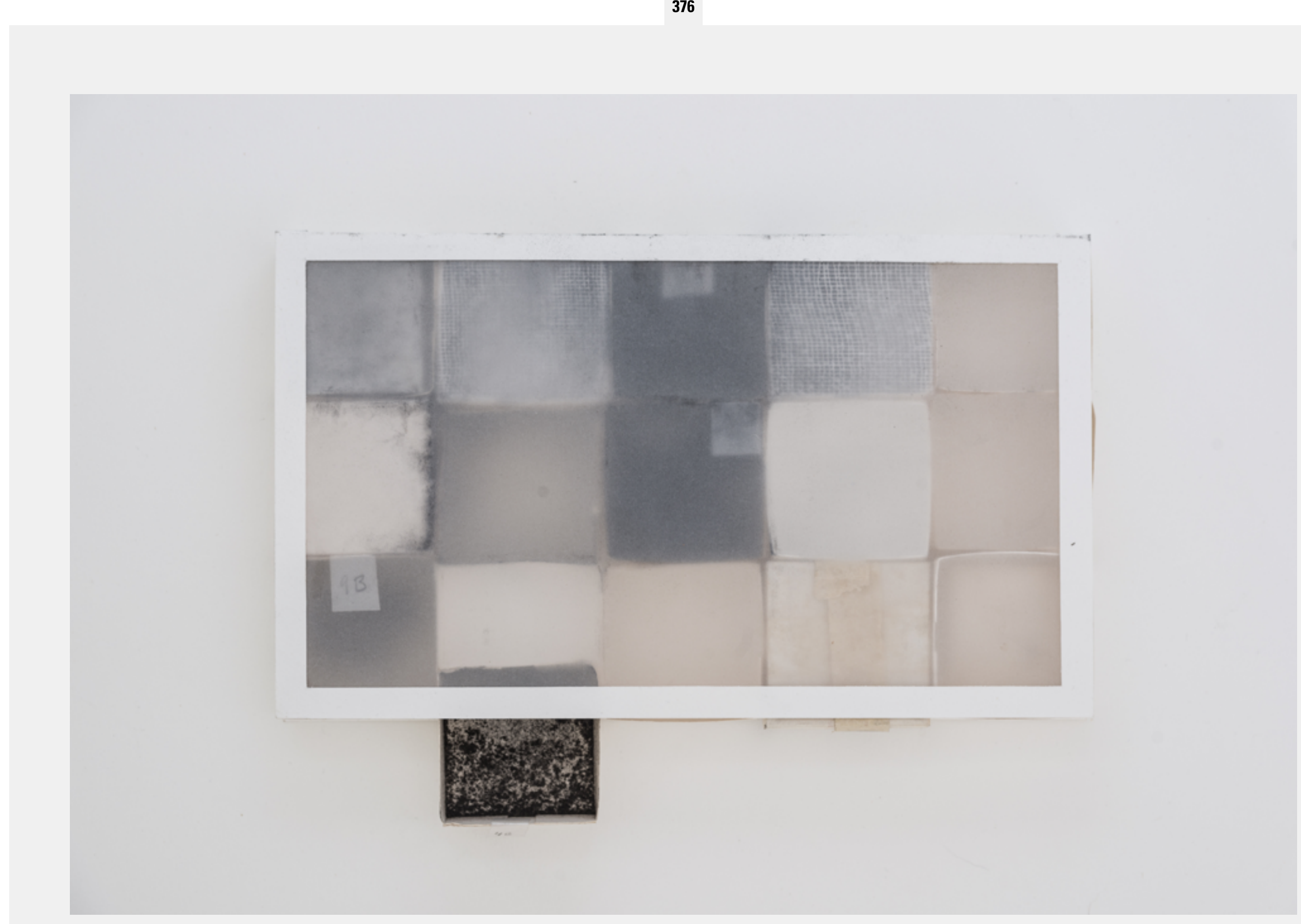

Biblioteca Para-Luz Foto: Ícaro Moreno 


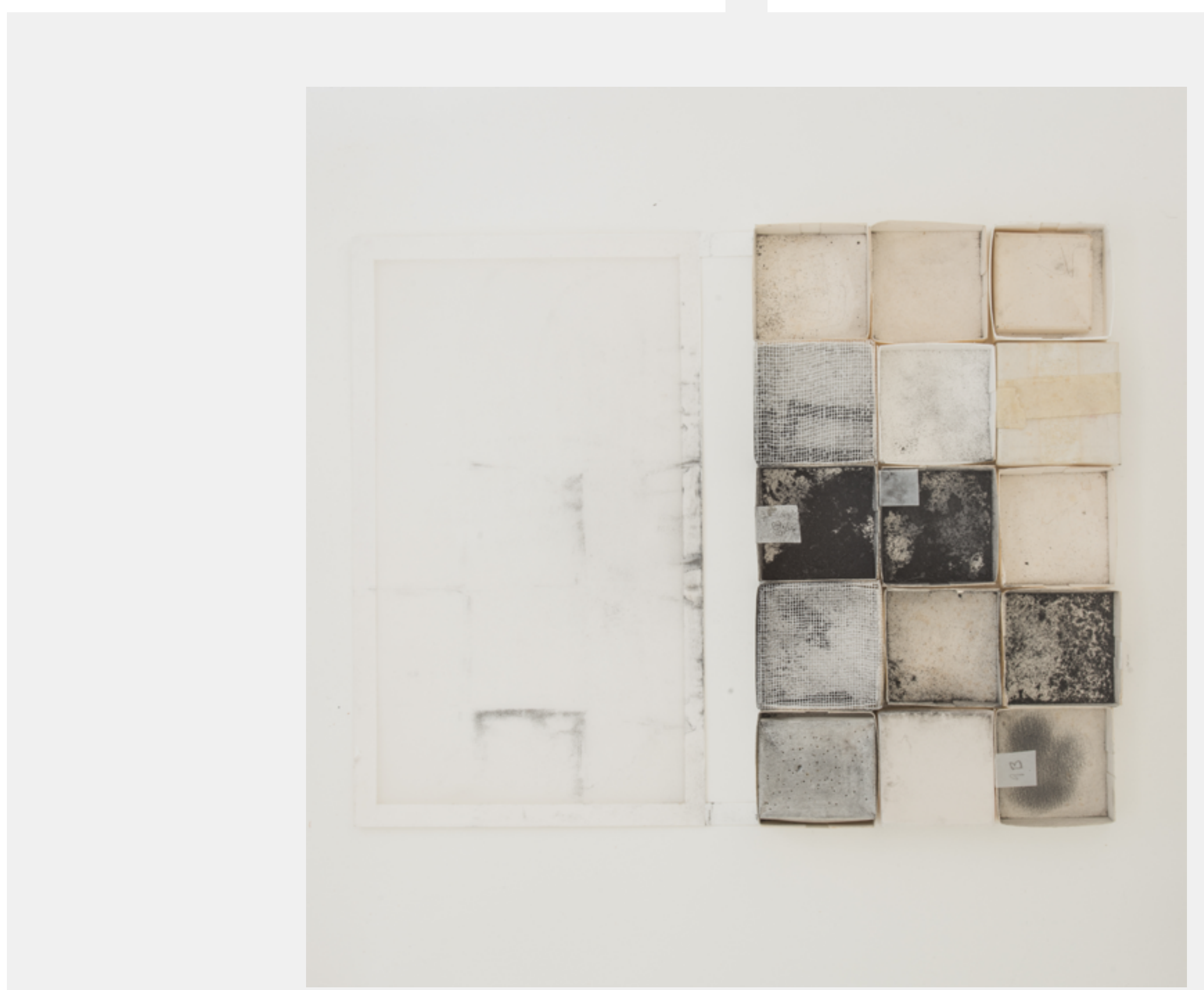

Biblioteca Para-Luz Foto: Ícaro Moreno 


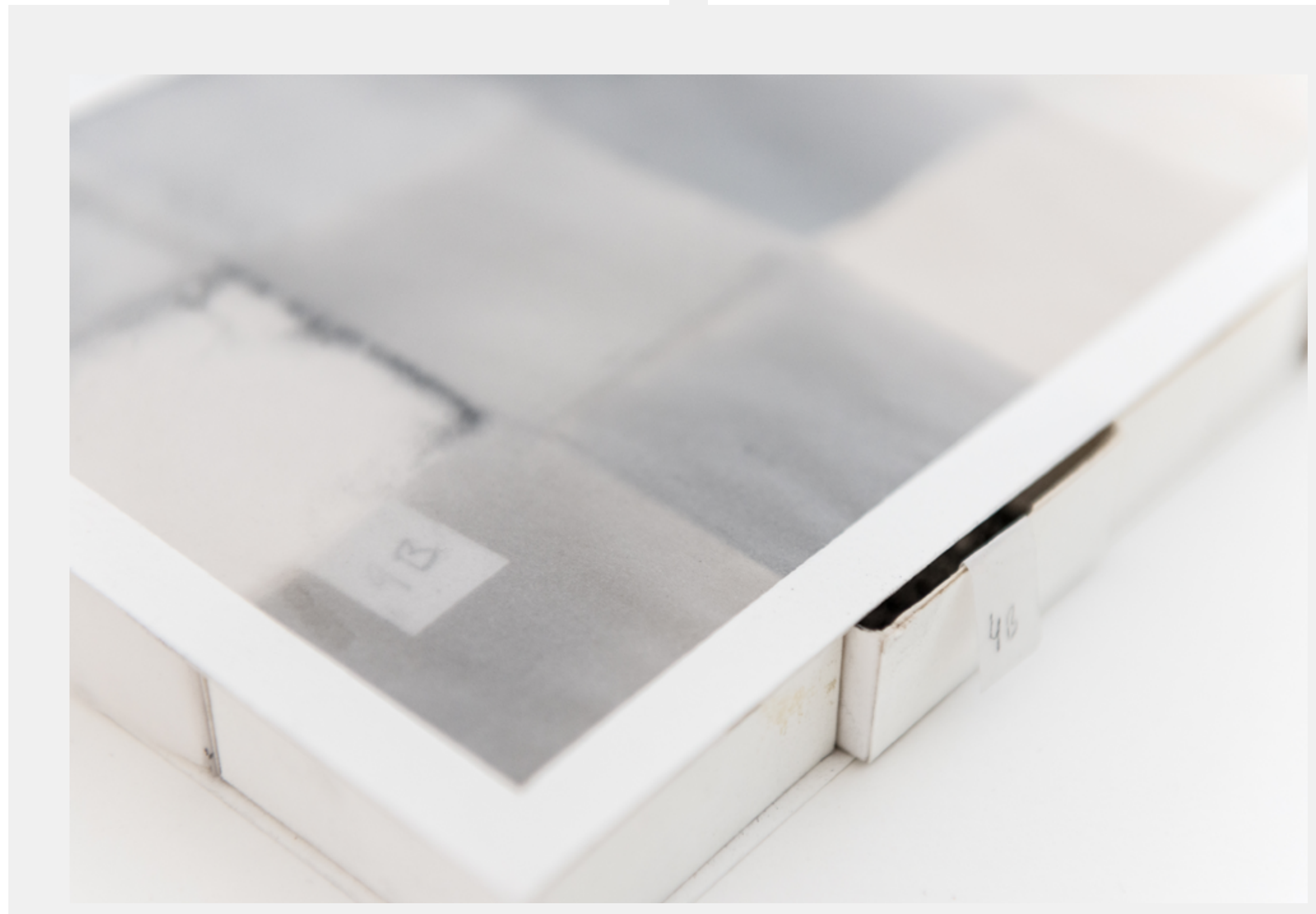

Biblioteca Para-Luz Foto: Ícaro Moreno 


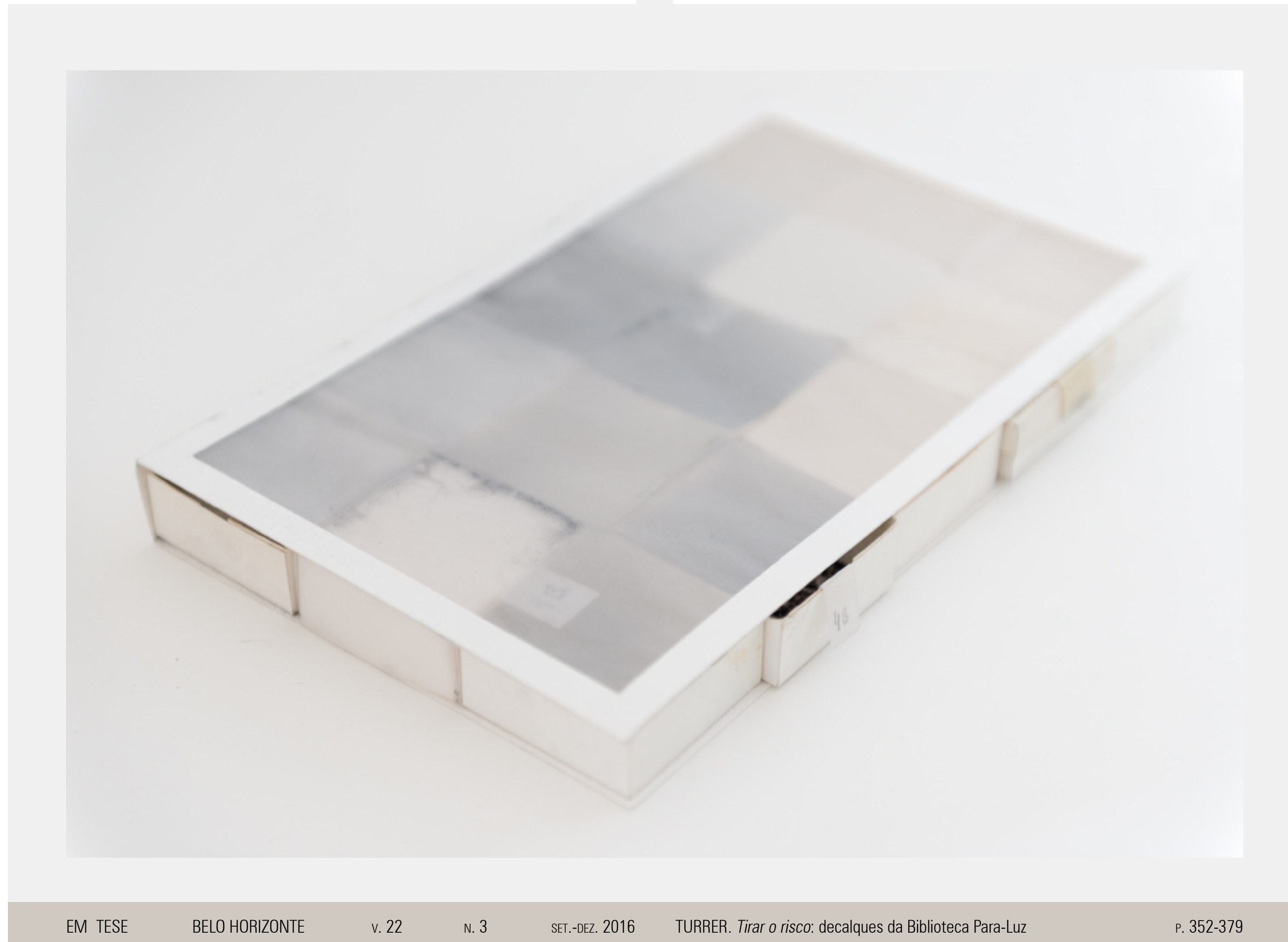

Biblioteca Para-Luz Foto: Ícaro Moreno 